\title{
PENGARUH PENDIDIKAN KESEHATAN TENTANG TABLET TAMBAH DARAH (TTD) PADA KELAS IBU HAMIL TERHADAP KEPATUHAN IBU DALAM MENGKONSUMSI TABLET TAMBAH DARAH DI UPT BLUD PUSKESMAS MENINTING TAHUN 2018
}

\author{
Astuti Setiawati ${ }^{1}$, Baiq Iin Rumintang ${ }^{2}$ \\ 1 Program Studi Diploma IV, Jurusan Kebidanan Poltekkes Kemenkes Mataram \\ 2 Program Studi Diploma IV, Jurusan Kebidanan Poltekkes Kemenkes Mataram
}

Abstrak

Latar Belakang : Tahun 2016, di Lombok Barat tercatat sekitar 12,07\% ibu hamil mengalami anemia dan meningkat pada tahun 2017 menjadi 15,62\%. Prevalensi anemia pada ibu hamil di wilayah kerja UPT BLUD Puskesmas Meninting tahun 2016 sebesar 27,01\%, dan meningkat menjadi 28,18\% tahun 2017, sehingga menduduki urutan tertinggi kedua untuk kasus anemia pada ibu hamil (Dikes Kabupaten Lombok Barat, 2017).

Tujuan : Untuk mengetahui pengaruh pemberian pendidikan kesehatan tentang tablet tambah darah (TTD) di kelas ibu hamil terhadap kepatuhan ibu hamil dalam mengkonsumsi TTD di UPT BLUD Puskesmas Meninting.

Metode : Jenis penelitian Pra-eksperimen dengan rancangan The One Group Pretest Posttest. Sampel penelitian yaitu ibu hamil yang memenuhi kriteria inklusi dan eksklusi sebanyak 30 orang dengan teknik purposive sampling. Intervensi yang dilakukan yaitu memberikan penyuluhan di kelas ibu hamil pada pertemuan ke-3 selama 20 menit. Analisis data menggunakan Marginal Homogeneity Test.

Hasil : Karakteristik peserta kelas ibu hamil sebagian besar berumur 20 - 35 tahun sebanyak 25 orang $(83,33 \%)$, tingkat pendidikan tamat SLTA sebanyak 11 orang $(43,33 \%)$, pekerjaan ibu rumah tangga sebanyak 23 orang $(76,67 \%)$, paritas multigravida sebanyak 15 orang $(50 \%)$, jarak kehamilan hamil pertama sebanyak 13 orang $(43,33 \%)$. Tingkat kepatuhan sebelum pendidikan kesehatan yaitu rendah sebanyak 25 orang (83,33\%), setelah pendidikan kesehatan tingkat kepatuhan tinggi sebanyak 16 orang $(53,34 \%)$. Hasil uji statistik menggunakan Marginal Homogeneity Test diperoleh $\mathrm{p}=0,000$.

Kesimpulan : Pendidikan kesehatan tentang tablet tambah darah (TTD) pada kelas ibu hamil berpengaruh terhadap kepatuhan ibu hamil dalam mengkonsumsi TTD di UPT BLUD Puskesmas Meninting.

Kata Kunci : Pendidikan Kesehatan, Kepatuhan, Tablet Tambah Darah, Kelas Ibu Hamil 


\title{
THE INFLUENCE OF HEALTH EDUCATION ABOUT ADDED BLOOD TABLETS IN THE PRENATAL CLASS ON MATERNAL COMPLIANCE IN TAKING ADDED BLOOD TABLET AT MENINTING PUBLIC HEALTH CENTER YEAR 2018
}

\author{
Astuti Setiawati, Baiq iin Rumintang \\ Diploma IV Program of Midwifery Health Polytechnic of Mataram
}

Abstract

Background : In 2016, in West Lombok around 12.07\% of pregnant women experienced anemia and increased in 2017 to $15.62 \%$. Anemia prevalence in pregnant women in the working area of the Meninting Public Health Center in 2016 was 27.01\%, and increased to 28.18\% in 2017, which was ranked second highest for cases of anemia in pregnant women (Health government in West Lombok District, 2017).

Objective: To know the effect of giving health education about added blood tablets in prenatal class on mother to compliance of pregnant mother in consuming blood tablets at Meninting Public Health Center.

Methods: Pre-experimental research with the design of The One Group Pretest Posttest. Research samples were pregnant women who met the inclusion and exclusion criteria as many as 30 people with purposive sampling technique. The intervention was carried out by giving counseling in the prenatal class at the 3rd meeting for 20 minutes. Data analysis uses Marginal Homogeneity Test. Result: Characteristics of class participants of pregnant women were mostly 20-35 years old as many as 25 people (83.33\%), high school graduated education level was 11 people (43.33\%), housewife work was 23 people $(76.67 \%)$, multigravida parity as many as 15 people $(50 \%)$, the distance of the first pregnancy was 13 people (43.33\%).

The level of adherence before health education was as low as 25 people $(83.33 \%)$, after health education a high level of compliance was 16 people (53.34\%). The results of statistical tests using Marginal Homogeneity Test obtained $\mathrm{p}=0,000$.

Conclusion: Health education about added blood tablets in prenatal class affects the compliance of pregnant women in consuming added blood tablets at Meninting Public Health Center.

Keywords: Health Education, Compliance, Added Blood Tablets, Prenatal Class

\section{PENDAHULUAN}

Undang-Undang No 36 tahun 2009 tentang kesehatan mengamanatkan bahwa upaya kesehatan bertujuan untuk menjaga kesehatan ibu sehingga mampu melahirkan generasi yang sehat, cerdas dan berkualitas, serta dapat menurunkan angka kematian ibu dan bayi. Upaya kesehatan sebagai mana di maksud pada undang-undang tersebut meliputi upaya promotif, preventif, kuratif dan rehabilitatif. ${ }^{1}$

Berdasarkan Profil kesehatan Kabupaten Lombok Barat 2017 tercatat sekitar 15,62\% ibu hamil mengalami anemia. Angka ini masih tinggi dibandingkan prevalensi anemia di Kota Mataram yaitu sekitar $5,46 \% .^{2}$

Prevalensi anemia pada ibu hamil di wilayah kerja UPT BLUD Puskesmas Meninting yang pada tahun 2016 sebesar 27,01\%, dan meningkat menjadi 28,18\% pada tahun 2017, sehingga UPT BLUD Puskesmas Meninting menduduki urutan tertinggi kedua untuk kasus anemia pada ibu hamil. ${ }^{3}$

Salah satu program yang dilaksanakan pemerintah untuk menanggulangi anemia gizi adalah pemberian Tablet Tambah Darah (TTD) sebagai suplemen zat besi untuk ibu hamil. Tablet Tambah darah (TTD) diperlukan untuk mencegah dan menanggulangi anemia defisiensi besi. 
Selama kehamilan, pemerintah membagikan sebanyak 90 TTD bagi setiap ibu hamil, yang diberikan mulai kehamilan trimester I. Perilaku yang masih perlu ditingkatkan adalah peningkatan konsumsi Tablet Tambah Darah pada ibu hamil.

Berdasarkan Profil Kesehatan Kabupaten Lombok Barat data cakupan pemberian TTD di Kabupaten Lombok Barat sudah cukup tinggi 94,69\% pada tahun 2016 namun pada tahun 2017 menurun menjadi 93,56\%.

Berdasarkan evaluasi gizi mikro UPT BLUD Puskesmas Meninting, data cakupan pemberian TTD pada tahun 2016 yaitu sekitar 95,68\% dan pada tahun 2017 sekitar 95,46\%. ${ }^{3}$

penyebab rendahnya kepatuhan ibu mengkonsumsi tablet suplemen dari ibu hamil sendiri adalah faktor kelupaan dan efek samping (mual, muntah, pusing), kurangnya kesadaran tentang pentingnya tablet suplemen dan ancaman anemia bagi ibu hamil, takut bayi lahir besar dan tidak ada konseling yang khusus dari tenaga kesehatan. ${ }^{4}$

Kelas ibu hamil merupakan kelompok belajar ibu-ibu hamil dengan umur kehamilan antara 4 minggu s/d 36 minggu (menjelang persalinan) dengan jumlah peserta maksimal 10 orang. Kegiatan kelas ibu hamil dibagi menjadi 4 pertemuan dengan materi yang berbeda-beda dalam setiap pertemuan. ${ }^{5}$

Sebelumnya pernah dilakukan penelitian oleh Sulastijah, Sumarni, dan Helmyati di Sukoharjo Jawa Timur tahun 2014 tentang Pengaruh Pendidikan Gizi Dalam Upaya Meningkatkan Kepatuhan Konsumsi Zat Besi Melalui Kelas Ibu. Peneliti tersebut memberikan pendidikan kesehatan tablet tambah darah dengan menggunakan media booklet anemia. Kemudian hasil penelitian didapatkan bahwa Pendidikan gizi berpengaruh meningkatkan kepatuhan konsumsi zat besi melalui kelas ibu hamil di Kecamatan Gatak Kabupaten Sukoharjo Jawa Timur. ${ }^{6}$

Penelitian serupa yang dilakukan oleh Sarah, di Pejeruk tahun 2015 tentang Pengaruh Tingkat Kepatuhan Minum Tablet $\mathrm{Fe}$ dengan Kejadian Anemia di Pejeruk. Peneliti melakukan pemantauan kepatuhan dengan menggunakan kuisioner MMAS-8. Dengan hasil penelitiannya, ada pengaruh antara tingkat kepatuhan minum tablet fe dengan kejadian anemia di UPT BLUD Puskesmas Pejeruk. ${ }^{7}$

Selama pelaksanaan kelas ibu hamil materi yang disampaikan adalah masalah kesehatan ibu dan anak, tidak ada materi khusus tentang tablet tambah darah.

Berdasarkan observasi awal yang peneliti lakukan terhadap 5 orang ibu hamil. Ditemukan 3 orang dengan kategori kepatuhan sedang, 2 orang dengan kepatuhan kurang.

Berdasarkan dari latar belakang peneliti tertarik untuk memberikan intervensi tentang "Pendidikan Kesehatan Tablet Tambah Darah di Kelas Ibu Hamil Terhadap Kepatuhan Mengkonsumsi Tablet Tambah Darah" yang akan dihubungkan dengan kuisioner Morisky Medication Adherence Scale (MMAS-8). Media pendidikan kesehatan yang akan diterapkan berupa pemberian materi dengan power point dengan demonstrasi cara minum TTD dalam kelas ibu hamil pada pertemuan ke 3 selama 20 menit.

\section{METODE}

Desain penelitian yang akan digunakan adalah Pre Experimental dengan pendekatan One Group Pretest-Posttest yaitu untuk mengetahui perbedaan dan perubahan pada nilai sebelum dan setelah dilakukan intervensi. ${ }^{8}$ Tempat yang digunakan dalam penelitian ini adalah di wilayah kerja UPT BLUD Puskesmas Meninting serta dilakukan penelitian selama 1 bulan. Populasi dalam penelitian ini adalah seluruh ibu hamil yang mengikuti kelas ibu hamil. Sampel untuk penelitian ini adalah seluruh ibu hamil yang memenuhi kriteria inklusi dan eksklusi, serta bersedia menjadi responden dalam penelitian dan menyetujui informed consent pada hari pertama.

Teknik pengambilan sampel pada penelitian ini secara purposive sampling yaitu dengan cara pengambilan sampel yang berdasarkan atas suatu pertimbangan tertentu seperti sifat-sifat populasi 
ataupun ciri-ciri yang diketahui sebelumnya. ${ }^{8}$ Besar sampel dalam penelitian ini sebanyak 30 orang.

Dalam penelitian ini yang menjadi Variabel Independen adalah Pendidikan Kesehatan tentang Tablet Tambah Darah. Sedangkan Variabel Dependen adalah Kepatuhan Ibu dalam Mengkonsumsi Tablet Tambah Darah.

Penelitian ini menggunakan data Primer yang dilakukan secara langsung oleh peneliti untuk mengolah data penelitian di UPT BLUD Puskesmas Meninting. Data dianalisis secara univariat dengan tabel distribusi frekuensi berdasarkan semua variabel, dan analisis bivariat dalam menguji hipotesi menggunakan uji Marginal Homogeneity (Uji Nonparametrik). ${ }^{8}$

\section{HASIL}

\section{A. Identifikasi Karakteristik:}

Tabel 4.1 Distribusi Responden Menurut Umur di UPT BLUD Puskesmas Meninting.

\begin{tabular}{|c|c|c|}
\hline Karakteristik & $\mathbf{n}$ & $\%$ \\
\hline \multicolumn{3}{|l|}{ Umur } \\
\hline$<20$ tahun & 2 & 6,7 \\
\hline $20-35$ & 25 & 83,3 \\
\hline$>35$ tahun & 3 & 10 \\
\hline \multicolumn{3}{|l|}{ Pendidikan } \\
\hline Tidak sekolah & 1 & 3,3 \\
\hline Tidak tamat SD & 2 & 6,7 \\
\hline Tamat SD & 4 & 13,3 \\
\hline Tamat SLTP & 6 & 20 \\
\hline Tamat SLTA & 13 & 43,4 \\
\hline Akademi/ Universitas & 4 & 13,3 \\
\hline \multicolumn{3}{|l|}{ Pekerjaan } \\
\hline Ibu rumah tangga & 23 & 76,6 \\
\hline Wiraswasta & 3 & 10 \\
\hline Pegawai swasta & 2 & 6,7 \\
\hline Pegawai negeri & 0 & 0 \\
\hline Lain-lain & 2 & 6,7 \\
\hline \multicolumn{3}{|l|}{ Paritas } \\
\hline Primigravida & 13 & 43,3 \\
\hline Multigravida & 15 & 50 \\
\hline Grandemulti-gravida & 2 & 6,7 \\
\hline \multicolumn{3}{|l|}{ Jarak Kehamilan } \\
\hline Hamil Pertama & 13 & 43,3 \\
\hline$<2$ Tahun & 2 & 6,7 \\
\hline 2-5 tahun & 6 & 20 \\
\hline$>5$ Tahun & 9 & 30 \\
\hline Total & 30 & 100 \\
\hline
\end{tabular}

(Sumber: Data Primer, 2018).

Berdasarkan tabel 4.1 diatas, dapat dilihat mayoritas umur 20 - 35 tahun sebanyak 25 orang $(83,3 \%)$, pendidikan tamat SLTA sebanyak 11 orang $(43,4 \%)$, pekerjaan ibu rumah tangga sebanyak 23 orang $(76,6 \%)$, paritas multigravida sebanyak 15 orang $(50 \%)$, jarak kehamilan hamil pertama sebanyak 13 orang $(43,3 \%)$.

B. Kepatuhan Peserta Kelas Ibu Hamil dalam Mengkonsumsi TTD Sebelum Dan Setelah Diberikan Pendidikan Kesehatan.

Tabel 4.2 Distribusi jumlah responden berdasarkan tingkat kepatuhan sebelum dan sesudah pendidikan kesehatan di UPT BLUD Puskesmas Meninting Tahun 2018. 


\begin{tabular}{|c|c|l|l|l|}
\hline \multirow{2}{*}{ Tingkat Kepatuhan } & $\begin{array}{c}\text { Sebelum Pendidikan } \\
\text { Kesehatan }\end{array}$ & \multicolumn{3}{c|}{ Setelah Pendidikan Kesehatan } \\
\cline { 2 - 5 } & $\mathbf{n}$ & $\%$ & $\mathbf{n}$ & \% \\
\hline Kepatuhan tinggi & 0 & 0 & 16 & 53,4 \\
\hline Kepatuhan sedang & 5 & 16,7 & 10 & 33,3 \\
\hline Kepatuhan rendah & 25 & 83,3 & 4 & 13,3 \\
\hline Total & $\mathbf{3 0}$ & $\mathbf{1 0 0}$ & $\mathbf{3 0}$ & $\mathbf{1 0 0}$ \\
\hline
\end{tabular}

( Sumber: Data Primer, 2018 )

Berdasarkan Tabel 4.2 diatas dapat dilihat bahwa dari 25 sampel $(83,3 \%)$ dengan tingkat kepatuhan rendah sebelum diberikan pendidikan kesehatan meningkat menjadi tingkat kepatuhan tinggi sebanyak 16 sampel $(53,4 \%)$.

\section{Pengaruh Pendidikan Kesehatan Tentang TTD Pada Kelas Ibu Hamil Terhadap Kepatuhan Ibu dalam Mengkonsumsi TTD.}

Tabel 4.3 Uji Marginal Homogeneity terhadap kepatuhan sebelum dan setelah dilakukan pendidikan kesehatan tentang tablet tambah darah pada kelas ibu hamil di UPT BLUD Puskesmas Meninting Tahun 2018.

\begin{tabular}{|l|c|}
\hline \multicolumn{2}{|c|}{$\begin{array}{c}\text { Marginal Homogeneity } \\
\text { Test }\end{array}$} \\
\hline & $\begin{array}{c}\text { Sebelum Pendidikan kesehatan \& Sesudah Pendidikan } \\
\text { kesehatan }\end{array}$ \\
\hline Observed MH Statistic & 73.000 \\
\hline Mean MH Statistic & 54.500 \\
\hline Std. Deviation of MH Statistic & 3.841 \\
\hline Std. MH Statistic & 4.817 \\
\hline Asymp. Sig. (2-tailed) & .000 \\
\hline
\end{tabular}

( Sumber: Data Primer, 2018 ).

Berdasarkan Tabel 4.3 Berdasarkan hasil Uji Marginal Homogeneity diperoleh nilai signifikansi adalah 0,000. Nilai $\mathrm{p}<0,05$ maka diputuskan Ho ditolak dan Ha diterima. Dengan demikian dapat disimpulkan bahwa ada perbedaan yang signifikan antara kepatuhan ibu sebelum dan setelah pendidikan kesehatan tentang tablet tambah darah pada kelas ibu hamil sehingga ada pengaruh pendidikan kesehatan tentang tablet tambah darah pada kelas ibu hamil terhadap kepatuhan ibu dalam mengkonsumsi tablet tambah darah di UPT BLUD Puskesmas Meninting Tahun 2018.

\section{DISKUSI}

\section{A. Karakteristik Responden Peserta Kelas Ibu Hamil.}

1. Umur

Pada penelitian ini berdasarkan tabel 4.1 dari 30 responden sebagian besar berumur 20 - 35 tahun sebanyak 25 orang $(83,3 \%)$.

Seperti yang kita ketahui, semakin tua umur seseorang maka proses perkembangan mentalnya bertambah baik, akan tetapi pada umur - umur tertentu, bertambahnya proses perkembangan mental ini tidak secepat ketika berusia belasan tahun, dengan demikian dapat disimpulkan faktor umur akan mempengaruhi tingkat pengetahuan seseorang yang akan mengalami puncaknya pada umur - umur tertentu dan akan menurun kemampuan penerimaan atau mengingat sesuatu seiring dengan usia semakin lanjut. Semakin muda seseorang semakin mudah pula menyerap apa yang disampaikan. Tidak hanya itu, semakin cukup umur, tingkat kematangan dan kekuatan seseorang akan lebih matang dalam berpikir dan mengambil suatu keputusan serta mempengaruhi kepatuhan. ${ }^{9}$ 


\section{Pendidikan}

Berdasarkan penelitian didapatkan ibu yang rutin mengikuti pendidikan kesehatan pada kelas ibu hamil dengan latar belakang pendidikan tamat SLTA/SMA, sebanyak 11 orang $(43,4 \%)$.

Latar belakang pendidikan ibu hamil berpengaruh terhadap kepatuhan ibu meminum tablet tambah darah. Tingkat pendidikan tinggi seharusnya memiliki wawasan lebih tentang kebutuhan selama kehamilan, namun kenyataannya beberapa dari mereka dengan tingkat pendidikan sekolah tinggi yang memiliki tingkat kesadaran yang cukup rendah. Hal ini disebabkan beberapa faktor, seperti kebiasaan malas, lupa, dan lain-lain.

Tingkat pendidikan seseorang akan berpengaruh dalam memberi respon terhadap sesuatu sehingga perbedaan tingkat pendidikan mengakibatkan perbedaan pengetahuan yang diperoleh responden tentang konsumsi tablet tambah darah. ${ }^{10}$ Tidak hanya itu seseorang yang tingkat pendidikannya rendah akan menghambat perkembangan sikap seseorang terhadap penerimaan informasi dan nilai-nilai baru yang diperkenalkan. ${ }^{7}$

\section{Pekerjaan}

Berdasarkan hasil penelitian ini, menunjukkan sebagian besar responden berstatus ibu rumah tangga yaitu sebanyak 23 orang $(76,6 \%)$.

Salah satu faktor struktur sosial yaitu pekerjaan akan mempengaruhi pemanfaatan pelayanan kesehatan, pekerjaan seseorang dapat mencerminkan sedikit banyaknya informasi yang diterima, informasi tersebut akan membantu seseorang dalam mengambil keputusan untuk memanfaatkan pelayanan kesehatan yang ada. ${ }^{5}$ Selain itu, lingkungan pekerjaan juga dapat menjadikan seseorang memperoleh pengalaman dan pengetahuan baik secara langsung maupun secara tidak langsung. ${ }^{8}$

\section{Paritas}

Berdasarkan penelitian ini, terlihat bahwa responden dengan jumlah paritas terbanyak yaitu multigravida sebanyak 15 orang $(50,0 \%)$.

Dalam hal paritas, semakin banyak jumlah gravida, semakin ibu hamil tidak patuh mengkonsumsi tablet tambah darah. Ibu hamil dengan kehamilan kedua, ketiga, dan seterusnya merasa kehamilan tersebut sebagai hal yang normal dan sudah biasa, sehingga konsep tersebut mengakibatkan menurunnya perhatian terhadap pemeliharaan kehamilannya. Keadaan tersebut mem-bahayakan bagi kesehatan ibu hamil, karena semakin tua umur ibu maka kondisi kesehatan semakin menurun. ${ }^{5}$

\section{Jarak Kehamilan}

Berdasarkan penelitian ini, terlihat bahwa responden banyak tidak memiliki jarak kehamilan atau merupakan hamil pertama, sebanyak 13 orang $(43,3 \%)$.

Jarak kehamilan juga merupakan hal yang penting untuk diperhatikan, kejadian anemia pada ibu hamil selain banyak disebabkan karena asupan gizi yang kurang juga terdapat faktor peneyebab lain yaitu jarak kehamilan yang terlalu dekat. Jarak kehamilan yang optimal adalah lebih dari 36 bulan kehamilan sebelumnya, sedangkan jarak jarak kehamilan yang dekat adalah kurang dari 2 tahun. ${ }^{11}$

Ada 2 orang respon dengan jarak kehamilan $<2$ tahun. Jarak kehamilan yang terlalu dekat menyebabkan ibu mempunyai waktu singkat untuk memulihkan kondisi rahimnya agar bisa kembali ke kondisi sebelumnya. Pada ibu hamil dengan jarak yang terlalu dekat beresiko terjadi anemia dalam kehamilan. Karena cadangan zat besi ibu hamil pulih. Akhirnya berkurang untuk keperluan janin yang dikandungnya.

Namun dari hasil penelitian terlihat bahwa karakteristik responden tidak terlalu berpengaruh terhadap kepatuhan ibu dalam mengkonsumsi TTD, karena walau tingkat pendidikan tinggi dan jumlah paritasnya yang banyak tetapi tingkat kepatuhan ibu masih dalam kategori kepatuhan rendah. Hal ini sesuai dengan penelitian sebelumnya yang 
menyatakan bahwa jumlah kehamilan ibu, tingkat pendidikan terakhir ibu, dan pekerjaan responden tidak berpengaruh $(\mathrm{P}>0,05)$ terhadap kepatuhan mengonsumsi zat besi. ${ }^{6}$

\section{B. Kepatuhan Ibu Hamil Dalam Mengkonsumsi TTD Sebelum dan Setelah Diberikan Pendidikan Kesehatan tentang TTD.}

Berdasarkan tabel 4.2 terlihat bahwa responden yang memiliki tingkat kepatuhan terbanyak sebelum diberikan pendidikan kesehatan yaitu kepatuhan rendah 25 orang $(83,3 \%)$, ditemukan hasil penelitian setelah diberikan pendidikan kesehatan responden terbanyak memiliki tingkat kepatuhan tinggi yaitu 16 orang $(53,4 \%)$ dan kepatuhan rendah sebanyak 4 orang $(13,3 \%)$.

Hal ini serupa dengan penelitian dari Aditianti (2015) yang mengukur kepatuhan ibu menggunakan kuisioner MMAS-8, menyebutkan bahwa sebelum dilakukan intervensi lebih dari $90 \%$ responden memiliki tingkat kepatuhan rendah dan tidak ada responden yang memiliki tingkat kepatuhan tinggi. Namun setelah dilakukan intervensi jumlah responden yang memiliki tingkat kepatuhan rendah menurun menjadi 13,3\% dan tingkat kepatuhan tinggi naik menjadi $10,3 \% .1^{2}$

Dari penelitian ini, dapat dilihat perubahan sebelum dan setelah diberikan pendidikan kesehatan. Sebanyak 11 orang dengan kepatuhan rendah meningkat menjadi kepatuhan tinggi, 10 orang dengan kepatuhan rendah meningkat menjadi kepatuhan sedang, kepatuhan sedang 5 orang meningkat menjadi kepatuhan tinggi, dan yang tetap memiliki tingkat kepatuhan rendah sebanyak 4 orang.

Adapun responden yang memiliki tingkat kepatuhan rendah jumlahnya banyak yaitu 25 orang $(83,3 \%)$, hal ini juga dapat terjadi karena ibu hamil merasa mual akibat rasa dan bau tablet. Selain itu tablet tambah darah yang dikonsumsi setiap hari menimbulkan rasa bosan, sehingga ibu hamil menjadi lupa dan malas untuk mengkonsumsinya. Sesuai dengan penelitian ini, item kuisioner MMAS-8 yang menjawab "tidak" sebelum diberikan pendidikan kesehatan yaitu item nomer 1 sebanyak 1 orang dan item nomer 8 sebanyak 2 orang. Item tersebut membahas tentang kesulitan seseorang dalam mengingat/lupa untuk mengkonsumsi TTD.

Hal lainnya yang menyebabkan rendahnya kepatuhan minum TTD yaitu karena kurangnya dukungan dari keluarga dalam hal memotivasi ibu bila merasa malas atau mual, mengingatkan untuk minum tablet tambah darah di malam hari, serta membawa TTD pada saat berpergian.

Hal ini sesuai dengan penelitian yang dilakukan oleh Ordenes dan Bongga pada tahun 2006. Pada penelitian tersebut alasan terbanyak ketidakpatuhan ibu karena lupa minum obat tablet besi $62 \%$, lupa membawa obat ketika mengunjungi keluarga $19 \%$, mengalami efek samping 16\%, lupa membawa obat tablet besi ketika bepergian keluar provinsi $9 \%$, ketersediaan obat habis $6 \%$, sibuk mengurus keluarga 3\%, memiliki tekanan darah tinggi $1 \%$, merasa sehat $1 \%$, ketakutan bahwa tablet besi dapat membahayakan bayi $1 \%$ dan nasehat bidan untuk mengkonsumsi tablet besi dilain waktu apabila tekanan darah tinggi $1 \% .{ }^{9}$

\section{Pengaruh Pendidikan Kesehatan Tentang TTD Pada Kelas Ibu Hamil Terhadap Kepatuhan Ibu Hamil Dalam Mengkonsumsi TTD}

Pada penelitian ini untuk menguji hipotesis menggunakan Uji Marginal Homogeneity dan didapatkan $\mathrm{p}$-value sebesar 0,000 . Nilai $\mathrm{p}<0,05$ artinya terdapat perbedaan yang signifikan kepatuhan ibu hamil dalam mengkonsumsi tablet tambah darah sebelum dan setelah diberi pendidikan kesehatan pada kelas ibu hamil. Dapat disimpulkan Ho ditolak dan Ha diterima artinya ada pengaruh pendidikan kesehatan tentang TTD Di kelas ibu hamil terhadap kepatuhan ibu hamil dalam mengkonsumsi TTD di UPT BLUD Puskesmas Meninting. 
Pada hasil penelitian ini didukung dengan metode yang dipakai dalam memberikan pendidikan kesehatan menggunakan metode ceramah pada pertemuan ketiga pada kelas ibu hamil, sebelumnya dilakukan pretest terhadap responden dengan menggunakan kuisioner MMAS-8. Selanjutnya peneliti mempraktikan secara langsung cara meminum tablet tambah darah dengan menggunakan minuman yang mengandung vitamin C. Selain itu, dalamproses pemberian pendidikan kesehatan menggunakan media audiovisual seperti laptop dan powerpoint. Setiap responden diberikan leaflet agar memahami mengenai tablet tambah darah.

Kepatuhan terhadap konsumsi TTD di Indonesia masih rendah, yang secara umum diakibatkan oleh rendahnya pengetahuan mengenai TTD, diantaranya adalah tentang efek samping minum TTD, penyerapan besi, makanan dan obat yang mengganggu penyerapan dan mitos serta kepercayaan yang salah. Maka, dengan diberikannya pendidikan kesehatan tentang TTD diharapkan dapat menimbulkan motivasi dan antusiasme pada ibu untuk meningkatkan kepatuhan dalam mengkonsumsi TTD.

Pada kegiatan kelas ibu hamil, peneliti memberikan tips agar ibu hamil tidak merasa mual pada saat mengkonsumsi TTD yaitu dengan meminum TTD bersamaan dengan jus jeruk atau jus buah asli lainnya, dan untuk mengatasi ibu hamil yang sering lupa yaitu dengan meletakkan TTD pada daerah yang sering terlihat oleh ibu, misalkan atas TV atau samping meja tidur.

Pengetahuan penting peranannya dalam menentukan kepatuhan dalam mengkonsumsi TTD, karena berpengaruh pada perilaku ibu hamil dalam menyimpan dan mengkonsumsi TTD secara teratur setiap harinya. Dengan diberikan materi tambahan pada kelas ibu hamil tentang TTD ibu hamil dapat lebih memahami seberapa penting TTD pada saat masa kehamilan. Pemberian demonstrasi secara langsung cara minum TTD yang benar juga berpengaruh dalam meningkatkan daya ingat ibu hamil dan perlu sering dibicarakan dalam kelas ibu hamil.

Hasil penelitian ini sejalan dengan penelitian yang dilakukan oleh Sulastijah pada tahun 2015 yang menyatakan kepatuhan pada kelompok kelas ibu hamil relatif lebih baik. Ini bisa terlihat dari meningkatnya persentase kepatuhan tiap bulan, kendati persentase kepatuhan pada bulan ketiga tidak naik secara bermakna. ${ }^{6} \mathrm{Hal}$ ini disebabkan oleh faktor pengetahuan yang diperoleh responden di kelas ibu hamil makin membaik, ini sesuai dengan penelitian sebelumnya yang menyebutkan bahwa pengetahuan ibu hamil tentang anemia defisiensibesi akan berpengaruh terhadap kepatuhan mengonsumsi tablet besi responden. ${ }^{6}$

Dan penelitian ini juga sesuai dengan teori yang menyatakan menggunakan metode ceramah dan demonstrasi, responden menjadi lebih cepat memahami dan mengingat materi tentang pentingnya tablet tambah darah yang telah diberikan oleh peneliti. ${ }^{13}$ Responden lebih cepat menyerap materi dari apa yang telah dilihatnya, sehingga metode demonstrasi lebih efektif dibandingakan metode ceramah. ${ }^{14}$

\section{Simpulan}

Karakteristik peserta kelas ibu hamil sebagian besar berumur 20 - 35 tahun sebanyak 25 orang $(83,3 \%)$, tingkat pendidikan responden tamat SLTA sebanyak 11 orang $(43,4 \%)$, pekerjaan responden sebagian besar merupakan ibu rumah tangga sebanyak 23 orang $(76,6 \%)$, paritas responden multigravida sebanyak 15 orang $(50 \%)$, jarak kehamilan responden sebagian besar hamil pertama sebanyak 13 orang $(43,3 \%)$.

Kepatuhan responden sebelum diberi pendidikan kesehatan tentang tablet tambah darah pada kelas ibu hamil termasuk rendah sebanyak 25 orang $(83,3 \%)$. Setelah diberi pendidikan kesehatan mayoritas meningkat menjadi tinggi sebanyak 16 orang $(53,4 \%)$. 
Ada pengaruh $(\mathrm{p}=0,000, \mathrm{p}<0,05)$ pendidikan kesehatan tentang tablet tambah darah pada kelas ibu hamil terhadap kepatuhan ibu dalam mengkonsumsi tablet tambah darah Di UPT BLUD Puskesmas Meninting.

\section{Ucapan Terima Kasih}

Ucapan Terima Kasih Penulis Sampaikan kepada ibu-ibu yang menjadi responden penelitian ini serta semua pihak yang telah membantu khususnya pada bidan koordinator, bidan desa dan kader wilayah kerja UPT BLUD Puskesmas Meninting yang telah membantu sehingga penelitian ini bisa terlaksana sesuai dengan yang direncanakan.

\section{DAFTAR PUSTAKA}

1. Ratna, Juwita. 2016. Hubungan Tingkat Kepatuhan Mengkonsumsi Tablet Fe Dengan Kejadian Anemia Pada Ibu Hamil dan Faktor-faktor Yang Mempengaruhinya di Wilayah Kerja Puskesmas Sikijang Kabupaten Pelalawan Tahun 2015. Masters Thesis: Universitas Andalas.

2. Dinas Kesehatan Kabupaten Lombok Barat. 2017. Laporan Pemantauan Wilayah Setempat Kesehatan Ibu dan Anak Kota Mataram 2016. Mataram: Dikes Kabupaten Lombok Barat

3. Profil UPT BLUD Puskesmas Meninting. 2017

4. Rumintang, Iin, Halimatusyaadiyah, dan Sundayani. 2016. Optimalisasi Konsumsi Tablet Tambah Darah untuk Peningkatan Kadar Hemoglobin (Hb) Pada Ibu Hamil Anemia Defisiensi Besi Ringan Sedang di Puskesmas Kota Mataram. Poltekkes Kemenkes Mataram

5. Lestari, D.D. 2015. Pengaruh Pendidikan Kesehatandan SMS Reminder Terhadap Kepatuhan Ibu Hamil dalam Mengkonsumsi Tablet Besi di Wilayah Kerja Puskesmas Pisangan Tahun 2015. Jakarta: UIN Syarif Hidayatullah.

6. Sulastijah, S, Sumarni, dan Helmyati. 2015.Pengaruh Pendidikan Gizi dalam Upaya Meningkatkan Kepatuhan Konsumsi Zat Besi Melalui Kelas Ibu Hamil di Kecamatan Gatak Kabupaten Sukoharjo. Jurnal Gizi Klinik Indonesia

7. Sarah, S. 2016. Pengaruh Tingkat Kepatuhan Ibu Hamil Dalam MengkonsumsiTablet Fe dengan Tingkat Kejadian Anemia di Puskesmas Pejeruk. Skripsi. Poltekkes Mataram

8. Notoatmodjo, S. 2014. Metodologi Penelitian Kesehatan. Jakarta: Rineka Cipta

9. Kertiasih, N.W dan Ani, L.S. 2013. Kepatuhan Minum Tablet Besi pada Ibu Hamil di Wilayah Kerja Puskesmas Mengwi I Kabupaten Bandung. Denpasar: Univeristas Udayana.

10. Sulistiyanti, A. 2015. Hubungan Tingkat Pengetahuan Ibu Hamil tentang Anemia dengan Konsumsi Tablet Fe di Wilayah Kerja Puskesmas Masaran 1 Sragen.

11. Putri, Meidila. 2016. Hubungan Peran Tenaga Kesehatan Terhadap Kepatuhan Ibu Hamil dalam Mengkonsumsi Tablet Fe. Yogyakarta : Universitas

12. Aditianti, Yurista, dan Elisa. 2015. Pendampingan Minum Tablet Tambah Darah (TTD) Dapat Meningkatkan Kepatuhan Konsumsi TTD Pada Ibu Hamil Anemia. Bogor: Pusat Teknologi Terapan Kesehatan dan Epidemiologi Klinik

13. Notoatmodjo, S. 2012. Promosi Kesehatan Dan Imu Perilaku Kesehatan. Jakarta: Rineka Cipta

14. Nisa, Khoirun. 2013. Pengaruh Pelatihan Tentang Pijat Bayi Terhadap Ketereampilan Ibu melakukan Pijat Bayi di BPS Kusni Sri Mawarti Desa Terong Kecamatan Dlingo Kabupaten Bantul Yogyakarta. Yogyakarta: Stikes Aisyiyah. 